\title{
Introduction aux articles de Anne-marie Autissier et de Jean-Michel Djian
}

Anne-Marie Autissier

\section{(2) OpenEdition}

1 Journals

Édition électronique

URL : http://journals.openedition.org/communicationorganisation/2327

DOI : 10.4000/communicationorganisation.2327

ISSN : $1775-3546$

Éditeur

Presses universitaires de Bordeaux

Édition imprimée

Date de publication : 1 mai 2000

ISSN : 1168-5549

Référence électronique

Anne-Marie Autissier, «Introduction aux articles de Anne-marie Autissier et de Jean-Michel Djian », Communication et organisation [En ligne], 17 | 2000, mis en ligne le 27 mars 2012, consulté le 04 mai 2019. URL : http://journals.openedition.org/communicationorganisation/2327 ; DOI : 10.4000/ communicationorganisation.2327

Ce document a été généré automatiquement le 4 mai 2019.

(c) Presses universitaires de Bordeaux 


\title{
Introduction aux articles de Anne-marie Autissier et de Jean-Michel Djian
}

\author{
Anne-Marie Autissier
}

1 Nous avons eu, Jean-Michel Djian et moi-même, le privilège de travailler « sur le terrain de l'Europe culturelle », dès l'année 1985. Fondateurs d'une Agence française des Jeunes créateurs européens, intitulée Eurocréation, nous nous sommes trouvés en contact avec des centaines de jeunes gens (20-25 ans) qui, de Séville à Amsterdam, s'efforçaient de tisser des liens artistiques et intellectuels au-delà des frontières nationales. Plus tard l'engagement de Jean-Michel Djian, en tant que co-directeur d'un DESS de Management culturel en Europe, et le mien à la tête de la publication Culture Europe, ont prolongé et revivifié cette connaissance des rouages européens, auprès de collègues, enseignants et chercheurs, et d'étudiants de second et de troisième cycle.

Lors de nos communications dans ce cadre, nous avons eu tout loisir de constater à quel point le discours sur l'Europe - et en particulier l'Europe culturelle - reposait sur des conventions de langage dans lesquels une certaine vulgate politique s'emparait de catégories aussi complexes et discutables qu'«identité », "mémoire commune », " culture européenne », pour en faire des slogans.

En bref, avant même de nous poser, à notre tour, l'intéressant problème d'une communication "visant à créer un espace qui rende possible le dépassement des différences ", il convient de rappeler à quel point les malentendus (peut-être nécessaires) et les glissements de sens en tous genres, ont fabriqué ce que nous n'hésiterons pas à qualifier de leurres.

4 L'une des grandes difficultés du processus européen en cours est certainement son caractère souterrain quoique volontariste, difficilement « reliable » quoique fédérateur, à peine pensable, quoique très influent. C'est pourquoi, en matière de communication, il nous semble aujourd'hui très important en Europe, de provoquer toutes les opportunités de partage, en nous fondant sur une communauté d'approche, beaucoup plus que sur une identité commune, au demeurant insaisissable. Dans le travail engagé par Culture Europe en coopération avec quelque quarante journaux et revues aujourd'hui en Europe, de l' 
Independent à/Kathimerini, via Die Zeit et la Nezavissimaïa Gazeta, le point de vue de l'éditeur que nous sommes, consiste à choisir des articles ou extraits d'articles chez nos correspondants espagnols, danois ou hongrois - choix qui n'est jamais contesté par nos interlocuteurs, même s'il ne croise pas toujours leurs priorités. De même, lorsque, par exemple, nous traitons le thème de l'« exception culturelle » à l'échelle de l'Europe, nous demandons à des auteurs de plusieurs pays de nous livrer leur vision, voire leur incompréhension sur la façon dont nous posons le problème ${ }^{1}$. "Se hâter de travailler ensemble tout en se gardant de conclure sur la nature de cette collaboration", serait notre devise à ce stade de nos activités et de nos recherches.

\section{NOTES}

1. Les échos de cette querelle sémantique se sont prolongés jusqu'au choix de l'expression de " diversité culturelle », aujourd'hui employée dans les instances européennes et internationales. 